\title{
RADIATION-INDUCED CHROMOSOME ABERRATIONS AND SISTER CHROMATID EXCHANGES IN LYMPHOCYTES FROM PATIENTS WITH TUBEROUS SCLEROSIS
}

\author{
Sumio Iujma, ${ }^{1}$ Makoto Higurashi, ${ }^{1}$ Tatsuya Takeshita, ${ }^{1}$ \\ Yoko KaWASAKI, ${ }^{2}$ and Masuko FuNAHASHI ${ }^{2}$ \\ ${ }^{1}$ Department of Health Sciences, Yamanashi Medical College, \\ Tamaho, Nakakoma, Yamanashi 409-38, Japan \\ ${ }^{2}$ Tama Habilitation Clinic for Child Neurology, \\ Nishifu, Fuchu, Tokyo 183, Japan
}

\begin{abstract}
Summary Lymphocytes from four patients with tuberous sclerosis (TS) and four normal controls were studied for sister chromatid exchanges (SCEs) and chromosome aberrations in gamma-ray irradiated cultures. There was no significant difference between SCE frequencies of TS $1 \mathrm{ym}$ phocytes and those of control lymphocytes at all doses examined $(1,2$, and 4 Gy). However, chromosome aberrations in TS lymphocytes were significantly higher than those in the normal controls at the highest dose (4 Gy) $(\mathrm{p}<0.05)$.
\end{abstract}

\section{INTRODUCTION}

Tuberous sclerosis (TS) is an autosomal dominant neurocutaneous disease. It has been reported that the frequencies of chromosome aberrations in lymphocytes from the TS patients are higher than those in lymphocytes from normal persons (Suzuki, 1977). Furthermore, there are some reports indicating that fibroblasts and lymphocytes from TS patients are hypersensitive to gamma-ray and $N$-methyl$N^{\prime}$-nitro- $N$-nitrosoguanidine (Scudiero et al., 1981; Paterson et al., 1982). Roos (1977) reported that the frequencies of spontaneous SCEs in cells from TS patients were normal and we reported that the SCE response to mitomycin C (MMC) was also within the normal range (Iijima et al., 1985). However, there are no reports about radiation induced chromosome aberrations and SCEs in lymphocytes from TS patients. The present experiment was performed to examine the induction of chromosome aberrations and SCEs by gamma-ray in lymphocytes from TS patients.

Received October 13, 1987; revised version received January 28, 1988; Accepted March 22, 1988 


\section{MATERIALS AND METHODS}

Analysis of siter chromatid exchange. Heparinized peripheral blood samples were obtained from four TS patients and four healthy controls. Whole blood from each donor $(0.3 \mathrm{ml})$ was added to $5 \mathrm{ml}$ RPMI 1640 medium (GIBCO) containing $15 \%$ fetal bovine serum (GIBCO) and $1 \%$ penicillin-streptomycin (GIBCO). The medium also contained $40 \mu \mathrm{M}$ bromodeoxyuridine (BUdR, Sigma) for the entire culture period. The blood samples in the media were exposed to gamma-rays emitted from a 4,000 $\mathrm{Ci}{ }^{137} \mathrm{Cs}$ source at doses of 1,2 and $4 \mathrm{~Gy}$. Immediately after the irradiation, $0.15 \mathrm{ml}$ of phytohemagglutinin $\mathrm{M}(\mathrm{GIBCO})$ were added to each culture. The cultures were incubated at $37^{\circ} \mathrm{C}$ for $72 \mathrm{hr}$ in a $\mathrm{CO}_{2}$ incubator. Colcemid $\left(2 \times 10^{-7} \mathrm{M}\right.$ final concentration, Wako $)$ was present in each culture during the last $6 \mathrm{hr}$. The cells were then collected by centrifugation, exposed to $0.075 \mathrm{M} \mathrm{KCl}$ hypotonic solution for $8 \mathrm{~min}$, and fixed three times in ethanol : acetic acid $(3: 1)$. Air dried chromosome preparations were made, and a modification of the fluorescenceplus-Giemsa (FPG) method of Goto et al. (1978) was applied to obtain the sister chromatid differential staining. Thirty metaphase cells in the second-division were scored for SCEs per dose point per person.

Chromosome aberration analysis. In the case of chromosome aberration analysis, the medium did not contain BUdR. The cultures were incubated for $54 \mathrm{hr}$. Colcemid was present in each culture during the last $28 \mathrm{hr}$ to arrest the cells in their first division. Chromosome preparations were stained with Giemsa. Dicentrics and rings were scored for chromosome aberrations. Fifty first-division metaphase cells were analyzed per dose point per person. The other methods used were the same as those presented above for the analysis of SCEs.

\section{RESULTS}

The frequencies of SCEs in TS and control cells are summarized in Table 1. The baseline SCE frequencies in the TS and control cells were $8.4 \pm 0.5$ and $8.6 \pm 0.5$, respectively. Gamma doses of 1 and 2 Gy did not increase these baseline frequencies. Although a dose of $4 \mathrm{~Gy}$ increased the SCE frequencies in both TS cells and normal cells, the increase was not significantly different and the response of the TS and normal cells were similar at all doses studied.

The number of dicentrics and rings per cell in TS and control cells are summarized in Table 2. The baseline frequencies of dicentrics and ring chromosomes per cell in TS and normal cells were $0.005 \pm 0.009$ and $0.003 \pm 0.004$, respectively. This difference was not significant. The gamma ray treatment led to a clear doserelated increase in the frequencies of dicentrics and rings in both groups. At doses of $1 \mathrm{~Gy}$ and $2 \mathrm{~Gy}$, the TS cells showed rather higher frequencies but the frequencies were not significantly different from those in the control cells. However, at $4 \mathrm{~Gy}$, 
Table 1. The frequencies of SCEs in cells obtained from patients with tuberous sclerosis and normal controls exposed to gamma-ray.

\begin{tabular}{lccccc}
\hline \multirow{2}{*}{ Donor } & \multicolumn{5}{c}{ Gamma-ray dose (Gy) } \\
\cline { 3 - 6 } & 1 & $7.8 \pm 0.7^{\mathrm{a}}$ & $8.3 \pm 0.8$ & $9.0 \pm 0.7$ & $11.2 \pm 0.7$ \\
TS & 2 & $9.8 \pm 1.0$ & $7.7 \pm 0.5$ & $7.8 \pm 0.7$ & $11.0 \pm 1.1$ \\
& 3 & $7.1 \pm 0.5$ & $8.2 \pm 0.7$ & $8.2 \pm 0.7$ & $8.0 \pm 0.6$ \\
& 4 & $8.7 \pm 0.7$ & $9.1 \pm 0.7$ & $8.5 \pm 0.5$ & $10.9 \pm 0.6$ \\
\multirow{2}{*}{ Mean } & & $(8.4 \pm 0.5)$ & $(8.3 \pm 0.3)$ & $(8.4 \pm 0.2)$ & $(10.3 \pm 0.7)$ \\
Normal & 1 & $8.6 \pm 0.7$ & $9.0 \pm 0.7$ & $8.4 \pm 0.7$ & $9.9 \pm 0.8$ \\
& 2 & $10.0 \pm 0.8$ & $8.6 \pm 0.5$ & $9.9 \pm 0.6$ & $10.5 \pm 0.7$ \\
& 3 & $8.5 \pm 0.7$ & $9.1 \pm 0.6$ & $9.6 \pm 0.8$ & $10.9 \pm 0.9$ \\
& 4 & $7.4 \pm 0.6$ & $9.0 \pm 0.7$ & $9.6 \pm 0.8$ & $10.4 \pm 0.7$ \\
\multirow{2}{*}{ Mean } & & $(8.6 \pm 0.5)$ & $(8.9 \pm 0.1)$ & $(9.4 \pm 0.3)$ & $(10.4 \pm 0.2)$ \\
\hline
\end{tabular}

a Mean \pm S.E.

Table 2. Frequencies of dicentric and ring chromosomes after exposure of TS and normal lymphocytes to various doses of gamma-ray.

\begin{tabular}{|c|c|c|c|c|c|}
\hline \multirow{2}{*}{ Donor } & & \multicolumn{4}{|c|}{ Gamma-ray dose (Gy) } \\
\hline & & 0 & 1 & 2 & 4 \\
\hline \multicolumn{6}{|l|}{ TS } \\
\hline & 1 & 0.02 & 0.08 & 0.21 & 1.42 \\
\hline & 2 & 0.00 & 0.08 & 0.24 & 1.63 \\
\hline & 3 & 0.00 & 0.19 & 0.46 & 1.89 \\
\hline & 4 & 0.00 & 0.25 & 0.71 & 2.26 \\
\hline Mean & & $0.005 \pm 0.009^{\mathrm{a}}$ & $0.150 \pm 0.073$ & $0.405 \pm 0.201$ & $1.800 \pm 0.313^{b}$ \\
\hline \multicolumn{6}{|l|}{ Normal } \\
\hline & 1 & 0.00 & 0.08 & 0.26 & 1.15 \\
\hline & 2 & 0.01 & 0.11 & 0.24 & 1.42 \\
\hline & 3 & 0.00 & 0.10 & 0.39 & 1.37 \\
\hline & 4 & 0.00 & 0.16 & 0.38 & 1.38 \\
\hline Mean & & $0.003 \pm 0.004$ & $0.113 \pm 0.029$ & $0.318 \pm 0.068$ & $1.330 \pm 0.106$ \\
\hline
\end{tabular}

${ }^{a}$ Mean $上$ S.D. $b$ Significantly higher $(\mathrm{p}<0.05$, Student's $t$-test) than the corresponding control value.

the frequencies in TS $(1.800 \pm 0.313)$ and normal cells $(1.330 \pm 0.106)$ differed significantly $(\mathrm{p}<0.05)$.

Vol. 33, No. 3, 1988 


\section{DISCUSSION}

In accord with the findings of Roos (1977), the present study showed that the baseline SCE frequencies in the peripheral blood lymphocytes from TS patients are in the normal range. We (1985) reported that there were no significant differences in the SCE frequencies between the lymphocytes from TS patients and those from normal controls exposed to various doses of MMC. Although SCEs were known to be rather refractory to ionizing radiation (Latt et al., 1980), Hafez et al. (1986) found that the frequencies of SCEs in the cells from patients with neurofibromatosis, another neurocutaneous disease, significantly increased with increasing doses of gamma-ray irradiation. However, the present study showed that there is no significant difference in the SCE frequencies between gamma-ray irradiated TS and normal cells. This suggests that the neurofibromatosis cells may be more unstable than TS cells.

At $4 \mathrm{~Gy}$, the frequency of chromosome aberrations in the cells of the TS patients was significantly increased over that in the cells from the normal controls. It has been reported that some of the cultured cell strains from TS patients were hypersensitive to gamma-ray or $N$-methyl- $N^{\prime}$-nitro- $N$-nitrosoguanidine (Scudiero et al., 1981; Paterson et al., 1982; Yoshida et al., 1985). These results and those of the present study indicate that hypersensitivity to radiation is an intrinsic feature of TS cells.

Acknowledgments This work was supported in part by a grant from the Ministry of Health and Welfare of Japan, and by a Grant-in-Aid for Scientific Research from the Ministry of Education, Science and Culture of Japan.

\section{REFERENCES}

Goto, K., Maeda, S., Kano, Y., and Sugiyama, T. 1978. Factors involved in differential Giemsastaining of sister chromatids. Chromosoma 66: 351-359.

Hafez, M., Abd, EL-Nabi, S.M., EL-Wehedi, G., and AL-Tonbary, Y. 1986. Enhanced response to the induction of sister chromatid exchange by gamma radiation in neurofibromatosis. Cancer 57: 1937-1940.

Iijima, S., Higurashi, M., Takeshita, T., and Funahashi, M. 1985. Spontaneous and mitomycin-C induced sister chromatid exchanges in cells from patients with tuberous sclerosis. Proc. Jpn. Acad. 61B: 32-34.

Latt, S.A., Schreck, R.R., Loveday, K.S., Dougherty, C.P., and Shuler, C.F. $1980 . \quad$ Sister chromatid exchanges. In Advances in Human Genetics, Vol. 10, Harris, H. and Hirschhorn, K., eds., Plenum Press, New York and London, pp. 267-331.

Paterson, M.C., Sell, B.M., Smith, B.P., and Bech-Hansen, T. 1982. Impaired colony-forming ability following irradiation of skin fibroblasts from tuberous sclerosis patients. Radiat. Res. 90: 260-270.

Roos, R.P. 1977. An immunological and cytogenetic investigation of tuberous sclerosis. Annu. Neurol. 1: 192-194. 
Scudiero, D.A., Moshell, A.N., Scarpinato, R.G., Meyer, S.A., Clatterbuck, B.E., Tarone, R.E., and Robbins, J.H. 1981. Lymphoblastoid lines and skin fibroblasts from patients with tuberous sclerosis are abnormally sensitive to ionizing radiation and to a radiomimetic chemical. $J$. Invest. Dermatol. 78: 234-238.

Suzuki, Y. 1977. Cytological study in tuberous sclerosis. J. Pediatr. Practice (Japan) 40: 353358 (in Japanese).

Yoshida, Y., Hayashi, A., and Arima, M. 1985. Rapid rejoining of X-ray induced DNA singlestrand breaks in tuberous sclerosis fibroblasts. Mutat. Res. 146: 211-218. 